\section{Profissionais de saúde no processo de vacinação contra hepatite $B$ em duas unidades básicas de Belo Horizonte: uma avaliação qualitativa}

\section{Health professionals in the process of vaccination against hepatitis $B$ in two basic units of Belo Horizonte: $A$ qualitative evaluation}

\section{Annelisa Santos Lages'}

Elisabeth Barboza França'

\section{Maria Imaculada de Fátima Freitas"}

'School of Medicine of the Federal University of Minas Gerais. Belo Horizonte, MG.

"School of Nursing of the Federal University of Minas Gerais. Belo Horizonte, MG.

Corresponding author: Annelisa Santos Lages. Universidade Federal de Minas Gerais, Escola de Enfermagem, Departamento de Enfermagem Materno-Infantil e Saúde Pública. Avenida Alfredo Balena, 190 - Santa Efigênia - 30130-100 Belo Horizonte, MG, Brazil. E-mail: annelisa.santos@gmail.com

\section{Abstract}

According to the Vaccine Coverage Survey, performed in 2007, the immunization coverage against hepatitis $\mathrm{B}$ in Belo Horizonte, for infants under one year old, was below the level proposed by the Brazilian National Program of Immunization. This vaccine was used as basis for evaluating the involvement of health professionals in the process of vaccination in two Basic Health Units (UBS, acronym in Portuguese) in the city. This study is qualitative and uses the notions of Social Representations Theory and the method of Structural Analysis of Narrative to carry out the interviews and data analysis. The results show flaws related to controlling and use of the mirror card and the parent orientation, and also the monitoring of vaccination coverage (VC) and use of VC data as input for planning health actions. It was observed that the working process in the UBS is focused on routine tasks, with low creativity of the professionals, which includes representations that maintain strong tendency to value activities focused on the health of individuals to the detriment of public health actions. In conclusion, the vaccination process fault can be overcome with a greater appreciation of everyday actions and with a much better use of local information about vaccination, and some necessary adjustments within the UBS to improve public health actions.

Keywords: Vaccination. Health services research. Qualitative research. Hepatitis B. Immunization coverage. 


\section{Resumo}

Em Belo Horizonte, a cobertura vacinal contra a hepatite $\mathrm{B}$ para menores de um ano foi aquém do preconizado pelo Programa Nacional de Imunização-PNI, de acordo com o Inquérito de Cobertura Vacinal realizado em 2007. A referida vacina foi então utilizada como fio condutor para esta pesquisa, que procurou avaliar o envolvimento dos profissionais de saúde no processo de vacinação, em duas unidades básicas de saúde (UBS) do município. O presente estudo é qualitativo e utiliza as noções da Teoria das Representações Sociais (TRS) e o método de Análise Estrutural de Narração para realizar a interpretação das entrevistas. Os resultados indicam que há falhas no que se refere ao controle e à utilização do cartão espelho, à orientação dos pais/ responsáveis, e também no monitoramento da cobertura vacinal (CV) e utilização dos dados de CV como subsídio para o planejamento das ações em saúde. Verificou-se que o processo de trabalho nas UBS está concentrado na rotina do serviço, com baixa criatividade dos profissionais, o que inclui representações que mantêm forte tendência à valorização de atividades voltadas à saúde individual em detrimento de atividades abrangentes de saúde coletiva. Conclui-se que a defasagem apresentada no processo de vacinação pode ser superada com uma maior valorização das ações cotidianas, com o uso mais adequado das informações geradas sobre a vacinação, e com o planejamento e incremento das atividades de saúde coletiva em nível local da atenção básica.

Palavras-chave: Vacinação. Avaliação em saúde. Pesquisa qualitativa. Hepatite B. Cobertura vacinal.

\section{Introduction}

The Brazilian Programa Nacional de Imunizações (PNI - National Immunization Program) is internationally recognized and aims to "control, eliminate and/or eradicate vaccine-preventable diseases that are considered priorities both to the Brazilian and to international public health" ${ }^{1}$. All governmental levels are responsible for its actions and the municipal government is in charge of organizing and structuring the municipal $\mathrm{PNI}^{2}$.

In spite of improvements in the immunization coverage in Brazil and in the information about the importance of vaccines, and despite their availability at municipal healthcare centers ${ }^{1}$, results of the Inquérito de Cobertura Vacinal (ICV - Vaccine Coverage Survey), which was carried out in 2007 in the city of Belo Horizonte (Southeastern Brazil), reveal that the coverage of the immunization against hepatitis B was low $-84.9 \%$, compared to the PNI's goal of immunizing $95 \%$ of the infants younger than 1 year old ${ }^{3}$. At some healthcare services in the city of Belo Horizonte, the coverage did not reach $60 \% 4$, which points to the existence of difficulties in the utilization and legitimation of this vaccine as a form of protecting individuals and the collectivity.

Hepatitis B is a public health problem in the world and in Brazil due to its high percentage of chronicity, to the severity of the disease and to the cost of the treatment, with medicines and liver transplantations. It affected 240 million people in $2005^{5}$.

Considering the findings of the Survey conducted in Belo Horizonte ${ }^{3}$ and the fundamental actors in the vaccination process, it is assumed that the low coverage of the immunization against hepatitis B in Belo Horizonte may be caused by imperfections in the monitoring of the actions and in the vaccination process performed at primary care units. Therefore, it is important to evaluate the vaccination process, that is, to investigate the extent to which the services are adequate to reach the expected results ${ }^{6}$ concerning the quality of the available 
resources. It should be emphasized that, in this field, the utilization of qualitative methodologies has been gradually increasing?

The quality of actions and the achievement of goals related to vaccination activities depend on the professionals' understanding and on their engagement in collective actions, which include, apart from the individual act of vaccinating, monitoring, supervision and consistent information. These actions do not depend exclusively on the number of professionals, but also on qualifications that enable the health professionals ${ }^{2}$ to gain knowledge and to develop attitudes related to the understanding of the working process and also to the involvement of the main actors in the developed actions. Due to this, in addition to the analyses about the evolution and expansion of the Sistema de Informação em Saúde (SIS - Health Information System) in the local and national scopes, it is necessary to study the utilization of the information by professionals as a subsidy to evaluate and plan actions at the Unidades Básicas de Saúde (UBS - Primary Care Units). The number of studies about the utilization of the Sistema de Informação da Atenção Básica (SIAB - Primary Care Information System) and of health management information has been increasing in the national literature ${ }^{8-10}$, but there are no evaluations about the use of information on vaccination by those who work within the healthcare system.

Therefore, this study aims to evaluate the vaccination process against hepatitis B in two UBS of Belo Horizonte, discussing the healthcare professionals' understanding and engagement in this process.

\section{Method}

This is a qualitative study that uses notions of the Social Representations Theory and the method of Structural Analysis of Narratives to interpret the interviews. Representations are considered here as the subjects' point of view about the object being investigated, according to Giami and Veil ${ }^{11}$.
To reveal the representations, the data were treated by the method of Structural Analysis of Narratives, described by Demazière and Dubar ${ }^{12}$, according to which the interview is a moment of reflection of the interviewee in the interaction with the interviewer, which enables the former to present his/her version of facts, justifications and feelings about them and about the people involved in the narrated facts or feelings; and the latter, to interpret, in the set of interviews, the categories of representations that support the daily routine of the vaccination work.

The interpretation of the interviews was divided into two stages. The first one corresponded to the analysis of each interview separately. At this stage, the first moment was of vertical reading ${ }^{13}$, in which the researchers searched for the global meaning of each interview. This provided them with the "tone" of the interview and enabled them to indicate the themes that were present in it. In a second moment of this stage, the deconstruction and reconstruction of each interview were performed, based on a horizontal reading ${ }^{13}$. The text was numbered according to a sequence and named according to what was revealed about the object of the discourse $\mathrm{e}^{14,15}$. Obviously, these objects are spread throughout the discourse, and the process to present and justify them is always characterized by comings and goings. Then, the objects and their explanations were regrouped, and the sequences were reconstructed and reorganized in the totality of the account, in an attempt to find, monitor and reproduce the work of categorization that the interviewee him/herself had performed. The second stage of the work consisted of finding, in a reading that Blanchet and Gotman ${ }^{13}$ called transversal, what was common and discordant in the set of empirical categories present in the interviews. Subsequently, the meanings that were explicit in the final corpus were grouped and categorized, the categories related to the representations were constructed, to be compared to the pertinent literature, and the reflections that closed the analysis were drawn. 
The first stage of fieldwork was to select the sanitary district and the UBS at which data collection would be carried out. The same criteria that were used to define the regional and local levels were employed: vaccine coverage below what the PNI recommends to control hepatitis B (95\%) and historical series analysis about the vaccine coverage of the respective services. Field recognition and the interviews were conducted between June and September 2011. The professionals responsible for the vaccination room were interviewed, as well as all the managers, nurses, general practitioners and pediatricians who compose the UBS teams, except for those who were on vacation, medical leave or who refused to participate $(\mathrm{n}=3)$. The interviews were scheduled according to the professionals' availability.

Data collection was guided by a script with indirect questions about the vaccine against hepatitis B, immunization coverage and the use of the vaccination record card, and the professionals were asked to talk about the vaccination activity at their work and about what they thought about this activity. The interviews were registered with an audio recorder, literally transcribed and interpreted with the aid of the Structural Analysis of Narratives.

The research was approved by the Ethics Committee for Research with Human Beings of the Municipal Health Department of Belo Horizonte (Opinion 0101.0.203.410-11 CEP/ SMSA/BH), and also by the Research Ethics Committee of the Federal University of Minas Gerais (Opinion 0101.0.203.410-11 COEP/UFMG). The authors state that there were no conflicts of interest in the conduction of the present study.

\section{Results}

The sanitary district (A) and the two UBS ( 1 and 2) that presented the lowest coverage against hepatitis B in 2010 were selected, according to the Technical Immunization Coordination of Belo Horizonte ${ }^{5}$ : $69 \%$ (95\%CI: 69.04; 71.97) for district A and 49\% (95\%CI: $44.18 ; 53.54)$ and $60 \%$ (95\%CI: 54.12 ; 64.54) for UBS 1 and 2, respectively. The historical series analysis showed descending curves for vaccine coverage against hepatitis $B$ in district $A$ and at UBS 1 and 2 (Figure 1), reaffirming the pertinence of the selection.

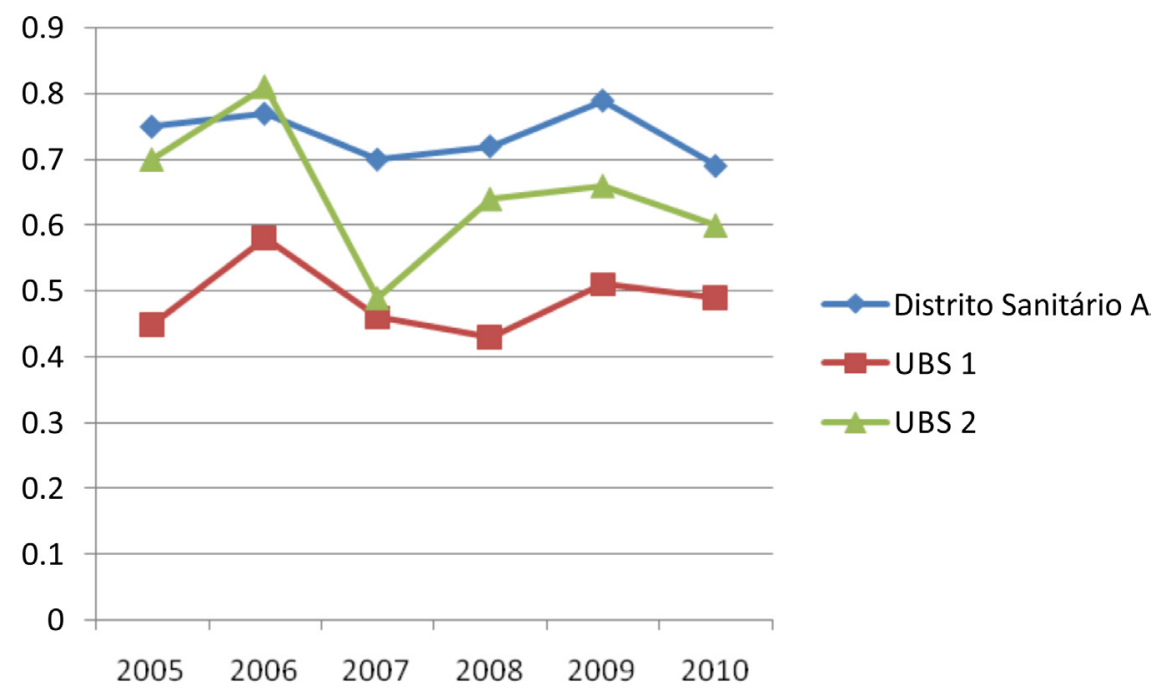

Fonte/Source: Secretaria Municipal de Saúde de Belo Horizonte. SMSA/BH

Figura 1 - Série histórica da cobertura vacinal contra a hepatite B para o distrito sanitário A, UBS 1 e UBS 2. Belo Horizonte, 2005-2010.

Figure 1 - Vaccination coverage against hepatitis $B$ for the health district $A$, UBS 1 and UBS 2. Belo Horizonte, 2005-2010. 
Twenty-six health professionals who work in equipes de saúde da família (ESFfamily health teams) or in other activities related to the UBS were interviewed. The doctors $(n=8)$ and nurses $(n=8)$ who are members of the ESF are generalists. The other interviewed professionals are generalist nurses (3), nursing technicians (2), pediatricians (4) and a general practitioner (1), and these professionals are not directly connected with an ESF. Concerning the interviewed professionals' age and the period of time during which they have been working at the UBS, the analysis showed that the former varied from 26 to 68 years, and the latter, from 3 months to 8 years.

It was possible to observe the presence of extremes regarding age and period of service at the two studied UBS; in addition, it was found that there were dissonances between the medical and the nursing professional concerning some aspects of the working process. Generally speaking, the health professionals have representations that can be grouped into three categories referring to the vaccination process and the other aspects involved in it: 1) Individual monitoring of vaccination: vaccination record card; 2 ) Collective monitoring of vaccination: vaccine coverage; and 3) Reflections on the low coverage of the vaccine against hepatitis B.

\section{Individual monitoring of vaccination: vaccination record card}

In the narratives, monitoring emerges as an activity performed in the services, at all moments of the children's contact with the UBS. However, the analysis of the discourses shows disjunctions, through affirmatives that deny this practice. Furthermore, not always is the vaccination record card used as an information instrument; it is not routinely used in active search, an activity that acquired a representation of unimportant strategy in health surveillance. Thus, two subcategories that encompass these representations emerged: a) monitoring children who are followed up at the UBS and b) active search.
Monitoring children who are followed up at the UBS

According to the professionals, the vaccination record cards are routinely checked during contacts with the children, either in scheduled consultations or in the assistance provided for acute cases. The children who use the UBS or belong to the Programa Saúde da Família (PSF - Family Health Program) are considered well monitored because "their vaccination card is up-to-date". One professional said: "What I see is the following: the patients who come to the office have no delayed vaccines". Apart from checking the card, the interviewees mentioned the conduct of instructing mothers and referring the child to the vaccination room when the card showed that some dose was delayed.

Checking the vaccination record card, which was emphasized by all the professional categories as a routine action, was minimized by three professionals of the medical area, who mentioned lack of time and of experience. Likewise, vaccination instructions are usually given only when "some problem" is identified. It is important to mention that one of the interviewees of this group, despite the explanations that had been given about the research, questioned his participation, as he is "not experienced in the infant schedule".

In addition, the activity of "providing instructions" for parents/guardians during the consultations and the subsequent referral to the vaccination room were presented as actions that are performed in the daily routine of the service, but not necessarily do they favor a good result, which can be seen in the following report: "Hey, are you late? Look! [showing the vaccination room to the mother]," "Oh yes. I'm going to take him there." "But sometimes she returns in the next visit and she hasn't taken the child there, you see?...".

In this subcategory, it is possible to conclude that the interviewees have representations according to which "the card of the children who attend the UBS is up-to-date", as "the cards are checked whenever the child 
Chart 1 - Main professional's representations about vaccination and other aspects involved in two UBS in Belo Horizonte, 2011.

Quadro 1 - Principais representações dos profissionais sobre a vacinação e demais aspectos nele envolvidos em duas UBS de Belo Horizonte, 2011.

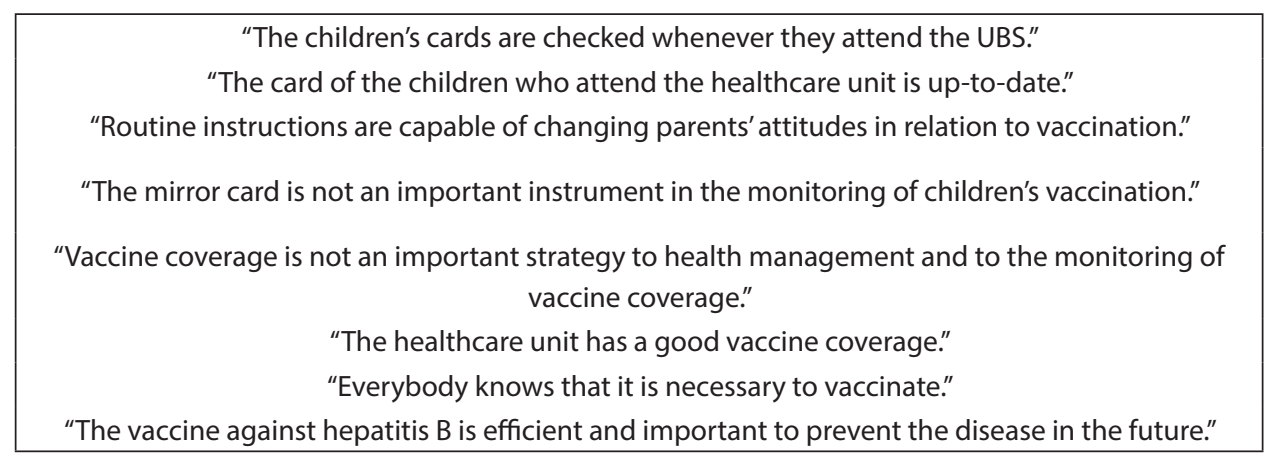

visits the UBS" and "the routine instructions are capable of changing the parents' attitudes towards vaccination" (Chart 1 ).

\section{Active search}

According to the interviewees, the active search is conducted at the healthcare units, although it is possible to state that there are disjunctions in the discourses and inconsistencies in this action. The reports are vague in relation to periodicity and the employed methodology, and show that the active search is performed "when the professionals have time", without being included as a systematic task in the working process: "[...] when we go to the vaccination room, when we have time, we have a look at the cards. We ask the ACS* to do the active search, but I myself don't go to the vaccination room every month to look at the cards that have delayed vaccines." The exception is one professional who says he performs this on a monthly basis, with the contribution of the ACS. However, even in this case, the detection of the child with delayed vaccines is performed only by the ACS during home visits; the "mirror card" that remains at the Unit is not considered an information instrument for it.

Another aspect is added to the inconsistencies reported above that minimizes the active search that is conducted at these healthcare units: the mirror card is rarely updated. The professionals report that, during vaccination campaigns, the flow of people in the vaccination room increases considerably and, thus, they do not have time to update the mirror card. Moreover, even when there is a separation of the mirror cards of children whose vaccines are delayed at the room's filing cabinet, they are not used in the active search; consequently, this is merely a bureaucratic activity.

\section{Collective monitoring of vaccination: vaccine coverage}

In this category, it is observed that the monitoring of vaccine coverage, as well as the information flow about it, is performed in an imperfect way at the two UBS. This makes the professionals ignore the low vaccine coverage that has been achieved by the UBS at which they work. Thus, two subcategories emerged regarding vaccine coverage: a) monitoring and information and b) professionals' representations about the data.

\section{Vaccine coverage: monitoring and} information

According to the manager of the Technical Immunization Coordination of the central level of the Municipal Health

*ACS = Agente Comunitário de Saúde (Community Health Agent). 
Department, the Vaccine Coverage (VC) of the UBS is calculated at the central level and sent, every semester, in the format of a report, to the sanitary district which, in turn, is responsible for sending this report to the UBS and discussing it. However, the data are not sent to the UBS with a systematic periodicity. Therefore, it is possible to state that the information flow about the vaccine coverage of the sanitary district to the UBS (Figure 2) has important imperfections, which may contribute to the professionals' posture of lack of responsibility towards vaccination, related to the representation that "everybody knows that it is necessary to vaccinate".

The nurses who are members of the ESF were questioned about the strategies used to monitor the vaccine coverage of the team's catchment area and the major part of the interviewees denied such action: "Look... Not exactly, there is no tool to do this". In addition, conducting team discussions at the local level or sending theVC information to the other UBS professionals were not mentioned (Figure 2).

The results of this study indicate that, at the local level, the vaccination activity

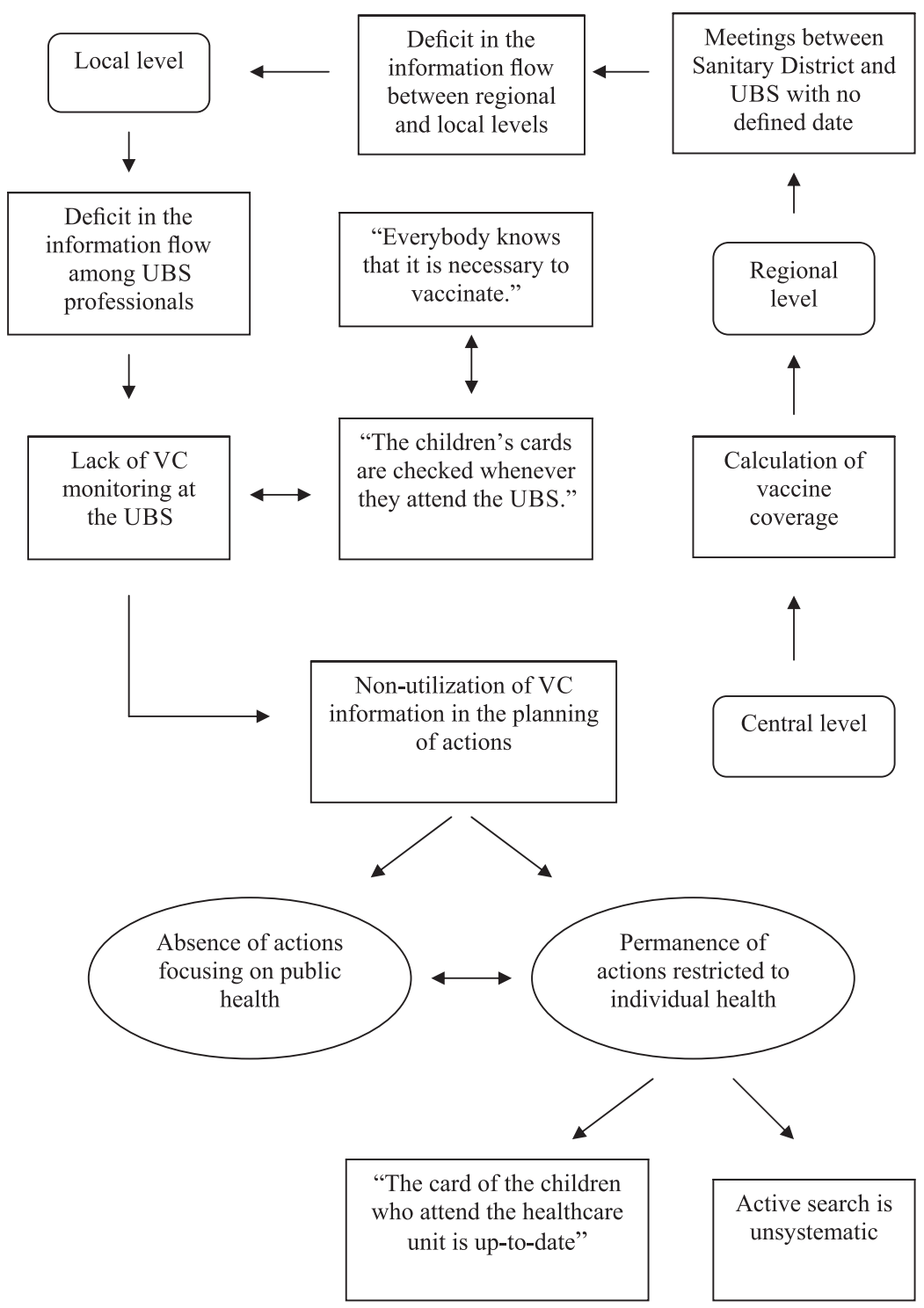

Figura 2 - Fluxograma do processo de vacinação em duas UBS de Belo Horizonte, 2011. Figure 2 - Flowchart of the process of vaccination in two UBS in Belo Horizonte, 2011. 
is seen with some indifference on the part of the professionals, as it is considered a routine action within a context of action fragmentation, information gaps and lack of data analysis and systematization. Therefore, the monitoring of vaccine coverage is incipient in the two studied UBS. The planning and evaluation for decision-making are represented as less important for the practice of the UBS.

It is remarkable, in the results that were found, that the focus of work at the two UBS is still anchored on individual health, which was revealed and is strengthened by the representation according to which "the card of the children who attend the healthcare unit is up-to-date" (Chart 1 ) and by the activity of active search, even though unsystematic. Obviously, such actions are insufficient, in view of the low coverage of the vaccine against hepatitis $B$. Therefore, the collective care action - VC monitoring - is not at the center of the agenda of these primary care units.

The professionals state that there are difficulties related to controlling the information regarding the low-risk population. Many aspects were listed, such as: this population is immunized at private clinics, there is resistance to being integrated into the healthcare unit, and there are no ACS to cover the area. For example, one professional reports that “(...) the low risk people, we don't have access to them. They get out of here and are immunized at the Institute J, or, after one week, they come back and are vaccinated in the campaign. So we can't keep this control."

Generally speaking, the results of this study point to the fact that vaccination, which was the flagship of Brazilian public health during years, is being relegated to the background in the daily routine of the services, due to the professionals' representation that it is a "trivial thing" and, therefore, something in which little is invested.

\section{Vaccine coverage: professionals'}

representations about the data

The news that the healthcare units participating in the research, as well as the municipality of Belo Horizonte, have low vaccine coverage against hepatitis $B$ for infants younger than one year old astonished some professionals: "Of the infants? Oh, my..." The local manager, in turn, hesitatingly declared his knowledge of the low coverage of the hepatitis vaccine: "No... I don't think this is happening here...".

About the VC data presented by Sanitary District A, the UBS professionals argued: "In fact, yesterday the epidemiology manager presented the indicators, and she talked about this issue of the vaccine coverage... But I think that the real coverage indexes - my impression is that they are not as bad as the statistics show.".

The professionals' lack of knowledge about the low coverage of the vaccine against hepatitis B, as well as their opinion, which is contrary to the data presented by the Municipal Health Department of Belo Horizonte, reveal representations about the "good vaccine coverage of the healthcare unit” (Chart 1). Such representations, in turn, maintain the professionals assured of the good monitoring of the children who attend the UBS, due to the fact that they make assessments through the service's apparent and daily demand - which is called "impression" -, and not through statistical data.

\section{Reflections on the low coverage of the vaccine against hepatitis $B$}

In relation to the possible causes of the low vaccine coverage against hepatitis $B$, the professionals presented diverse opinions, and mentioned, among others, mothers' lack of information and guidance, or neglect; parents' apprehension because of the infant's age; prolonged schedule, which may cause forgetfulness; professionals' lack of knowledge about the vaccine and difficulties in the administration technique. As for the supply of the vaccine against hepatitis B at the UBS, the central level manager highlights: "No, not hepatitis, the country already produces the vaccine, we have a large number of vaccines, so much so that each year the age group that is benefitted by the vaccine 
is extended. So, concerning hepatitis $B$, we don't have any problems related to its supply".

As for the postures of parents/guardians, the first representation presented by the UBS professionals was about the relationship between the form of administration and possible vaccine delays. The professionals responsible for the vaccination room reported that a child hardly leaves the UBS without being immunized when the dose is administered by an intramuscular injection. However, one interviewee stated that the difficulties are great and that the mothers are resistant to intramuscular administration.

The majority of the interviewees considered that parents/guardians are committed to the activity of vaccinating their children, qualifying the mothers as "careful" and conscientious" in relation to the dates of the vaccination schedule, although they sometimes do not know the objective of the vaccination. This consideration is probably related to the construction of the representation "everybody knows that it is necessary to vaccinate" (Chart 1), which indirectly contributes to the lack of vaccination monitoring at the UBS.

On the other hand, some UBS professionals question this adherence, arguing that the majority of the children whose vaccines are delayed live with mothers/guardians who have a difficult socioeconomic status and who "face problems like alcoholism, drug abuse, many children, among others".

\section{Discussion}

\section{Individual monitoring of vaccination: vaccination record card}

The medical professionals' narratives about the monitoring of the child's card reveal representations that exclude vaccination as an activity that is the responsibility of all health professionals. Other studies have already shown the low participation of doctors in the encouragement to vaccination, like the investigation about vaccination against influenza, in São Paulo, which showed that 153 doctors (35\%) refused to participate in the study because they believed that vaccination was not their problem ${ }^{16}$. About the efficiency of the instructions given to parents/guardians during the consultations that took place at the UBS, it should be highlighted that the interviewed professionals view these parents' behavior as "careless", which can be added to the stereotypes about the importance of vaccines that were presented above. This context of representations probably supports the low coverage of some vaccines, like the one against hepatitis $\mathrm{B}$, which leads to an inefficient detection of children, with low response to the active search of the ACS in the interval between consultations; in addition, the professionals do not take advantage of the fact that the children are already at the UBS to maintain the card up-to date. Therefore, the professionals believe that information, per se, would be enough for active postures on the part of parents/ guardians to immunize their children.

Thus, such practices, which are called health education, prove to be grounded on the conservative model, which aims at changing the individual's behavior ${ }^{17,18}$ without inclusion in a context and with no professional-user interaction that allows both to construct and reconstruct the meaning of the practices.

The reports on active search, in turn, revealed the transfer of function and of the responsibility for such task only to the ACS. This can be seen as a deviation in the process, as the ACS is not the only professional who is responsible for it. Thus, this discussion is similar to that of Tomás ${ }^{19}$ about the distortion of the work performed by the ACS. The author questions the "super-heroization" of this actor who, due to the absence of a specific description of their action, is overloaded at work.

As for the main instrument to perform the active search, the "mirror card", it was possible to conclude that the organization and correct filling of these cards represent only a bureaucratic activity. To Harris ${ }^{20}$, the probable reasons for the discrepancy 
between the mirror card and the child's card would be lack of training and of professionals to meet the increased demand during vaccination campaigns, as well as the population's lack of enrolment in vaccination activities. In the present study, it is possible, therefore, to state that the professionals have representations of non-valuation of the card as an information instrument for health promotion, and that these are the main obstacles to it being correctly filled and used.

\section{Collective monitoring of vaccination: vaccine coverage}

It is possible to observe that the interviewed professionals do not value the monitoring of vaccine coverage as a strategy to manage and program the health actions of the UBS, which is probably corroborated by the above-mentioned representation according to which "the children's cards are always checked at their home and on the day they attend the UBS" (Chart 1). Besides, the flow of data and information between the local and regional management presented important imperfections, such as absence of a previously defined date to send the vaccination reports and lack of an exclusive professional, in the regional level, to perform these activities. Thus, the opportunity to transform data into information is lost, and it is important to bear in mind that this information could be utilized as subsidy to the local management.

Bastos $^{8}$ also pointed at difficulties regarding the periodicity with which the Municipal Health Department of Rio de Janeiro presents data to the UBS, questioning the lack of management, in the same line of Benito 9 : “(...) information and its articulated flow in the working process in the area of health must be seen as the guiding axis to the potentialization and effectiveness of health actions, mainly within the healthcare network". In addition, Shout ${ }^{10}$ argues that an adequate information management is connected with "the institutional culture of information valuation", that is, of the feeling of participation and responsibility for information production and utilization.

Generally speaking, the results of this study point to the fact that vaccination, which was the flagship of Brazilian public health during years, is being relegated to the background in the daily routine of the services, due to the professionals' representation that it is a "trivial thing" and, therefore, something in which little is invested.

\section{Reflections on the low coverage of the vaccine against hepatitis $B$}

Regarding the barriers to achieve the goal of $100 \%$ of child immunization, França ${ }^{21}$ points to the lack of ACS and inputs, not to mention the parents' resistance to immunization, according to nurses who work in the PSF. This resistance is related to the infant's age, to representations of fragility or risk of getting sick due to the vaccine or simply because they do not know anyone who has the disease; thus, they do not consider that the vaccine is important.

Concerning adherence to the schedule of immunization against measles, Logullo ${ }^{22}$ argued that, many times, mothers delay their children's immunization in the case of injectable vaccines. Molina ${ }^{23}$ highlights that there is a trend of vaccine delay in children whose guardians have low level of schooling, in the same way that a lower number of children is significantly associated with up-to-date vaccination. Another aspect that interferes in the capacity to provide care for children is maternal depression and the presence of alcoholism in the family, a variable that indicates domestic stress ${ }^{24}$.

\section{Final Remarks}

Monitoring the vaccine coverage at the UBS is extremely important so that the objectives of control and eradication of vaccine-preventable diseases, proposed by the PNI, are fulfilled, avoiding the return of diseases that have already been controlled in Brazil. In this study, the assessment of the vaccination process at the UBS pointed to 
imperfections in the activities of monitoring the vaccination record card, providing instructions for parents/guardians, monitoring vaccine coverage and performing the active search.

There are differences in the working process in relation to the practice of monitoring the vaccination record card; fragmented observations favor the loss of the opportunity to vaccinate and the accumulation of susceptible individuals in the community. Correct information and the construction of new representations are instruments to empower parents/guardians, allowing a consistent approach to health and illness. These two activities, which should be part of the routine of the health professionals who work at the UBS, will only be incorporated by them when immunization and all its aspects are on the agenda of team meetings and discussions, which should be fostered by nurses and managers. Thus, reconstructing representations and breaking stereotypes, as part of the working process, are fundamental to the re-valuation of the vaccination activity as a public health action. However, social policies are also necessary, as low socioeconomic status, alcoholism, drug abuse and a large number of children were mentioned as factors that negatively affect children immunization.

The active search is a strategy that is not valued by the professionals, which generates gaps in what should be a system to capture those who have skipped vaccination; in addition, this discourages the professionals who are responsible for filling the "mirror card", as the cards are little utilized. Although the activity of active search should be performed by all the professionals, the nurses, especially the ones who work in the ESF, should be in charge of performing this activity and of stimulating the other colleagues to do the same.

The major part of the interviewees do not monitor VC, neither in their team nor in the UBS itself, which favors the professionals' ignorance about the children's vaccine situation and hinders the planning of health actions. This situation is promoted by the lack of local meetings to discuss and report the information received from the sanitary district and by the absence of an exclusive professional, in the sanitary district, to perform vaccination activities. In addition, the utilization of the private vaccination service in a mixed or exclusive way was also mentioned as a factor that hinders the monitoring of vaccine coverage, because there is not an efficient counter-referral to the Healthcare Center. However, strategies to monitor all the children of the catchment area can be strengthened, in addition to those that exist in private clinics.

Generally speaking, the results of this study indicate that concerning vaccination, the healthcare professionals of the two studied UBS perform their activities with central representations focusing on the health of the individual, to the detriment of public health. Despite the imperfections pointed in the vaccination process of such units, it is possible to consider that the professionals' representations are grounded on practices that do not imply daily accountability; therefore, they require greater investments in VC monitoring and in the updating of the children's vaccination cards, modifying the representations. However, it is important to stress the fact that representations are not easily reformulated, as they depend on the action of time and on professional interactions. These include information related to vaccination activities and their process at the unit, as well as the relationships with the other professionals, and also of these professionals with themselves.

This study approaches the assessment of a technological process - that of vaccination against hepatitis B at Primary Care Units. It is a qualitative study that does not intend to universalize its results. Its relevance to Public Health is the possibility of offering subsidies to improve the vaccination practice in the services. It is expected that the results can contribute to the conduction of other studies at other places, generating more knowledge about the vaccination process at healthcare units and leading to new strategies to enhance public health actions. 


\section{References}

1. Ministério da Saúde. Programa Nacional de Imunizações: 30 anos. Brasília: Ministério da Saúde; 2003.

2. Ministério da Saúde. Secretaria de Vigilância em Saúde. Manual de Rede de Frio. Brasília: Ministério da Saúde; 2010.

3. Luna EJA et al. Household survey of hepatitis B vaccine coverage among Brazilian children. Vaccine 2009; 27: 5326-31.

4. Secretaria Municipal de Saúde de Belo Horizonte. Coordenação Técnica de Imunização. Série Histórica das coberturas vacinais. Dados fornecidos pela Secretaria Municipal de Saúde de Belo Horizonte.

5. Ott JJ, Stevens GA, Groeger J, Wiersma ST. Global epidemiology of hepatitis B vírus infection: New estimates of age-specific HBsAg seroprevalence and endemicity. Vaccine 2012; 30: 2212-19.

6. Contandriopoulos AP, Champagne F, Denis JF, Pineault R. A avaliação na área da saúde: conceitos e métodos. In: Hartz, ZMA (org.). Avaliação em saúde. Dos modelos conceituais à prática na análise da implantação de programas. Rio de Janeiro: Editora Fiocruz; 1997. pp. 2948.

7. Gil CRR, Silva AMR, Campos JJB, Baduy RS. Avaliação em Saúde. In: Andrade M, Soares DA, Júnior LC (org.). Bases da saúde coletiva. Londrina: Editora UEL; 2001. pp. 125131.

8. Bastos MP. "Sistemas de informação em saúde: o uso no acompanhamento de pacientes hipertensos e diabéticos". Um estudo de caso do Sistema remédio em casa utilizado no município do Rio de Janeiro [dissertação de mestrado]. Rio de Janeiro: Escola nacional de Saúde Pública Sérgio Arouca; 2009.

9. Benito GAV, Licheski AP. Sistemas de Informação apoiando a gestão do trabalho em saúde. Rev Bras Enf 2009; 62: 447-50.

10. Schout D, Novaes HMD. Do registro ao indicador: gestão da produção da informação assistencial nos hospitais. Ciência e Saúde Coletiva 2007; 12: 935-44.

11. Giami A, Veil C. Enfermeiras frente à Aids: representações e condutas, permanência e mudanças. Canoas: ULBRA; 1997.

12. Demazière D, Dubar C. Analyser les entretiens biographiques: l'exemple de récits d'insertion. Paris: Nathan; 1997.

13. Blanchet A, Gotman A. L'enquete et ses méthodes: L'entretien. Paris: Nathan Université; 1992.
14. Freitas MIF, Oliveira SB, Giami A, Gomes AS, Silveira R, Guimarães MDC. Projeto Pessoas - Práticas e representações de pessoas com transtornos mentais sobre as infecções sexualmente transmissíveis e a aids e suas formas de prevenção. In: Guimarães MDC, Acúrcio FA, Possas CA, Sá M (organizadores). Prevenção e Atenção às IST/Aids na Saúde Mental no Brasil: Análises, desafios e perspectivas. Brasília: Ministério da Saúde; 2008. pp. 85-108.

15. Guimarães MDC, Acúrcio FA, Freitas M F et al. Projeto Pessoas - Metodologia dos componentes quantitativo e qualitativo. In: Guimarães MDC, Acúrcio FA, Possas CA, Sá M (org.). Prevenção e Atenção às IST/Aids na Saúde Mental no Brasil: análises, desafios e perspectivas. Brasília: Ministério da Saúde; 2008. p. 33-49.

16. Secretaria de Estado da Saúde de São Paulo. Centro de Referência em saúde do Trabalhador de São Paulo. Pesquisas indicam pequena participação dos médicos no incentivo à vacina contra influenza. Rev Saúde Pública 2004; 4: 606-8.

17. Cervera DPP, Parreira BDM, Goulard BF. Educação em saúde: percepção dos enfermeiros da atenção básica em Uberaba (MG). Ciênc Saúde Coletiva 2011; 16 (S1): $1547-$ 54 .

18. Trapé CA, Soares CB. Educative practice of community health agents analyzed through the category of praxis. Rev Latino-am Enfermagem 2007; 15: 142-9.

19. Tomáz JBC. O agente comunitário de saúde não deve ser um “super-herói”. Interface - Comunic Saúde Educ 2002; 10: $75-94$.

20. Harris WM. Utilização das fichas de registro de vacinação pelos centros de saúde na divisão regional de saúde de Campinas- Estado de São Paulo, Brasil. Rev Saúde Pública 1974; 8: 297-304.

21. França ISX. Cobertura vacinal e mortalidade infantil em Campina Grande, PB, Brasil. Rev Bras Enferm 2009; 62: 258-64.

22. Logullo P, Carvalho HB, Saconi, R, Massad E. Factors affecting compliance with the measles vaccination Schedule. Sao Paulo Med J 2008; 126: 166-71.

23. Molina AC, Godoy I, Carvalho LR, Júnior ALC. Situação vacinal infantil e características individuais e familiares do interior de São Paulo. Acta Sci Health Sci 2007; 29: 99-106.

24. Carvalhães MABL, Benício MHA. Capacidade materna de cuidar e desnutrição infantil. Rev Saúde Pública 2002; 36: 188-97.
Received: 05/04/12

Final version: 05/01/13

Approved: 15/01/13 